\title{
FATORES ASSOCIADOS AOS SINTOMAS DEPRESSIVOS EM IDOSOS INSTITUCIONALIZADOS
}

Leiliane Moraes dos Santos Silva; Universidade Federal de Pernambuco-UFPE; leiliane.moraes@ufpe.br

Crislayne Maria Berto; Universidade Federal de Pernambuco-UFPE; crislayneberto@gmail.com

Fernando Arthur Alves da Silva; Universidade Federal de Pernambuco-UFPE; fernando.arthur@ufpe.br Kimberly Mayara Gouveia Bezerra; Universidade Federal de Pernambuco-UFPE; kimberly.gouveia@ufpe.br

Ana Paula de Oliveira Marques; Universidade Federal de Pernambuco-UFPE; ana.marques@ufpe.br

\section{RESUMO}

Introdução: O Brasil é campeão nas estatísticas de ansiedade, afetando cerca de 9,3\% da população. Esses dados são mais alarmantes quando nos deparamos com a população senil do país. O Brasil é o sexto país do mundo em número de idosos, em 2020. Conforme a população brasileira envelhece, torna-se vulnerável às comorbidades psíquicas e fisiológicas. $\mathrm{O}$ impacto causado pela depressão está relacionado aos piores desfechos em saúde, aumento da fragilidade física, do risco de morte e na maior utilização de serviços de saúde. Objetivo: Revisar artigos que discutem os fatores associados a sintomas depressivos em idosos institucionalizados. Métodos: Revisão integrativa, com recorte temporal de 5 anos, nas bases de dados PubMed, Scielo, e Lilacs, utilizando a combinação dos descritores, em português, "Envelhecimento", "Idoso", "Depressão" e "Institucionalização". A partir dessa busca foram encontrados 10 estudos. Após a leitura, 5 estudos foram excluídos por não ser artigo, indisponibilidade na íntegra e repetição na base de dados, sendo selecionados 5 estudos. Resultados: A revisão categorizou os artigos em três temáticas: fatores associados aos sintomas depressivos, relação idoso-família e prevalência de fragilidade física. Observou-se que a visão negativa sobre a própria saúde se associou à sintomatologia depressiva. A autopercepção da saúde tem caráter multidimensional e determinará o comportamento do indivíduo. A perda das funções cognitiva, sexual, laboral e diminuição das relações socioculturais acarretam no aumento dos sintomas depressivos. Conclusão: A prevalência dos fatores associados aos sintomas depressivos identificados entre idosos institucionalizados alerta para a necessidade de maiores cuidados com a população idosa.

Palavras-chave: Envelhecimento; Idoso; Depressão; Institucionalização. 